Working Paper in Economics No. 690

\title{
Nudging à la carte - A field experiment on food choice
}

\section{Christina Gravert and Verena Kurz}

Department of Economics, February 2017 


\title{
Nudging à la carte -
}

\section{A field experiment on food choice ${ }^{1}$}

\author{
Christina Gravert ${ }^{\mathrm{a}}$ and Verena Kurz ${ }^{\mathrm{b}}$
}

31.01.2017

\begin{abstract}
We test the effect of framing of a menu on the choice of ordering climate friendly dishes in a randomized controlled experiment. Rearranging the menu in favor of vegetarian food has a large and significant effect on the willingness to order a vegetarian dish instead of meat. We show that there exists a considerable marginal group willing to change meat consumption behavior at least in the short term. Our results demonstrate both to policy makers and to actors in the food service sector that small, cheap interventions can significantly decrease carbon emissions from food consumption.

JEL classification: D12, Q50, C93
\end{abstract}

Keywords: Nudging, Field experiment, default, food choice

\section{Introduction}

The assumption of stable individual preferences is still one of the cornerstones of consumer theory. When given a choice between a number of options consumers should choose the option that maximizes their utility regardless of how the options are presented and the context they are put in, as long as the prices stay constant. However, a large amount of work in psychology and economics shows that this assumption is often violated (Slovic, 1995; Tversky and Simonson, 1993, Thaler and Sunstein 2008).

In this paper, we show how a small change in the framing of different options can have a substantial impact on the consumption choices individuals make. We test whether decreasing the convenience of ordering a meat dish and simultaneously increasing the convenience of ordering a vegetarian dish out of three dishes offered can decrease the sales of the meat option for vegetarian dishes.

\footnotetext{
${ }^{1}$ We thank Fredrik Carlsson, Randi Hjalmarsson, Katarina Nordblom, Mitesh Kataria, and Heiner Schumacher for comments. Part of this research was financed by a grant from the Swedish Environmental Protection Agency. ${ }^{a}$ Department of Economics, University of Gothenburg, Vasagatan 1, SE 41124 Göteborg, Sweden, Christina.gravert@economics.gu.se

${ }^{\mathrm{b}}$ Department of Economics, University of Gothenburg, Vasagatan 1, SE 41124 Göteborg, Sweden, Verena.kurz@economics.gu.se
} 
We conduct a field experiment with a restaurant to observe consumption choices. Over the course of three weeks, customers entering the restaurant were randomly presented with one of two menus. One menu offered a meat dish and a fish dish, with a note that a vegetarian option was available upon request. The other menu offered a vegetarian and a fish dish, with a note that a meat dish was available upon request.

We find that a small decrease in the convenience of the meat option, by making it necessary to ask the waiter to describe the dish, results in a significant decrease in the share of dishes containing meat sold at lunch, and an increase in the share of vegetarian and fish dishes. The share of meat dishes sold decreased from an average of $47 \%$, before the intervention to around $21 \%$ in the treatment condition, where it was not directly displayed on the menu.

The novelty of this study is the direct relevance for policy making. What we eat is an important determinant of both our health and our ecological footprint. Food production was responsible for about 16\% of global greenhouse gas (GHG) emissions in the period 2005-07 (Springmann et al., 2016). However, GHG emissions vary widely among types of foods. Diets rich in meat and dairy products entail higher $\mathrm{CO} 2$ emissions than plant-based diets. Tilman and Clark (2014) estimate that omnivorous diets are approximately four times higher in carbon intensity per calorie consumed than healthy vegetarian diets.

Although climate benefits from reduced consumption are estimated to be large ((Bryngelsson et al., 2016; Springmann et al., 2016; Westhoek et al., 2014)), there are currently no policy instruments in place that target meat consumption directly. "Meat taxes" are discussed in the scientific community (Säll and Gren, 2015; Wirsenius et al., 2011) but not implemented in any country yet. Initiatives, trying to encourage individuals to reduce meat consumption, such as "Meat-free days," are limited in their outreach and probably also in their effectiveness. Forced choice restrictions such as mandatory vegetarian days in school and canteens entail the risk of causing psychological reactance, and, ultimately, backlash (Lombardini and Lankoski, 2013).

Increasingly, researchers and policy makers call for behavioral interventions that neither change prices, choices, or the information that is given (so-called "nudges" (Thaler and Sunstein, 2008)) in order to promote sustainable consumption choices in the food domain (Girod et al., 2014; Lehner et al., 2015). While there is evidence that nudging can under some circumstances push people towards making healthier food choices (Just, 2009; Wansink, 2004; Wansink and Hanks, 2013; Wisdom et al., 2010), the evidence on the effectiveness of nudges for promoting sustainable food choices is very limited.

We close this gap in the literature by presenting the result of a simple nudge and its substantial effects on consumption. The results show that there is potential for restaurants to decrease the meat intensity of their dishes offered without banning meat items from the menu or changing prices. Our results demonstrate both to policy makers and to actors in the food service sector that small, cheap interventions can significantly decrease carbon emissions from food consumption. 
The paper continues as follows. Section 2 presents the experimental design. Section 3 presents the data and the experimental results. In Section 4 we discuss possible channels through which the nudge might influence behavior and give practical policy recommendations based on our findings.

\section{Experimental design}

The experiment was conducted for three weeks in May 2016 at a restaurant located in Gothenburg, Sweden. While serving à la carte during the evening and on weekends, there is a daily changing lunch menu during weekdays, which is available for two hours. Each day, the kitchen prepares three dishes for lunch: One containing meat, one with fish, and one vegetarian. All dishes include salad and bread and cost 110 SEK (approximately 13 USD). The restaurant has 52 seats and space for a handful of people at the bar. Our experimental treatments make use of two specific features of the restaurant setup: The architecture of the restaurant and the design of the lunch menu.

Regarding architecture, the restaurant has two areas, which are separately partly by a wall and partly by a bar acting as an almost physical border. The front part, where customers enter, has 30 seats. The back area has 22 seats. The lunch menu is printed each week anew on an A3 varnished paperboard and lists the options for the whole week. Proceedings during lunch are as follows: Once a customer or group of customers is seated, the waiter hands out the menus to the guests. If customers want to have a look at the menu before deciding if they want to eat at the restaurant or not, a waiter gets a menu sheet from the bar and hands it out to the customers. No menus are set up at the wall, at the entrance, or outside the restaurant. Our treatments build on this by letting the waiters hand out different menus to customers seated in the front area compared to customers seated in the back.

During the pre-experimental period, the weekly lunch menu listed two of the available three options: The option containing meat and the option containing fish. A vegetarian dish was available upon request and could be customized to a vegan version. However, nowhere on the menu, it was stated that a vegetarian/vegan dish was available. This menu was distributed throughout the whole restaurant, and sales data on the number of vegetarian, meat and fish dishes sold for lunch was collected on a weekly basis, for four weeks.

During the intervention, the waiters handed out two different menus at the restaurant. One menu contained, as before, the daily meat and fish options for the whole week, but had a sentence added stating "a daily changing vegetarian option is available on request." We added this sentence to check if simply giving information about the availability of a vegetarian dish could increase the sales of vegetarian dishes. Customers seated in the back part of the restaurant received this menu. The menu distributed to customers seated in the front differed by listing the vegetarian and fish dish, but not the meat option. The only hint towards the availability of a meat dish was the added sentence "a daily changing option containing meat is available on request." Thus, the menu distributed in the front made it slightly less convenient 
to order the meat dish ${ }^{2}$ : Customers had to call a waiter and ask what the dish was to be able to compare it to the options spelled out on the menu. On the other hand, the convenience of ordering the vegetarian dish increased for those customers seated in the front part, compared to the setup in the pre-experimental period and the back part of the restaurant during the experiment. The convenience of ordering the dish containing fish remained the same across periods and areas. In both menus, the fish dish was the second one presented on the menu. Consequently, the vegetarian and the meat dish were presented in the same spot. For convenience reasons, the meat and the vegetarian dish were usually the same except that the meat was replaced by a vegetable, grain or plant protein. Thus, the other components of the dish have a similar climate impact. Also, we can be sure that the side orders did not affect the choice. In addition to the lunch options, the menus also stated two desserts, which were the same across treatments and for the whole week.

The intervention lasted for three weeks, during which we collected daily sales data of the three lunch options by area in the restaurant, front and back. One advantage of the experimental design is that we have two control periods available. While the pre-experimental period mainly serves as a control to check if the behavior of the customers seated in the back part of the restaurant changes during the experimental period (which should not be the case), data from the back part itself serves the control group during the intervention period. By doing so, the control and the treatment group were subject to the same dishes available and to the same external factors, such as weather conditions, holidays and other daily variations in setting, which could otherwise act as confounding factors. A major advantage of this design is that we can control for an important event happening during our study; due to unexpectedly nice weather during May, the restaurant opened its outdoor serving already on May $9^{\text {th }}$ instead of $1^{\text {st }}$ of June as originally planned. The restaurant staff made sure to define different areas of approximately the same size also in the outdoor serving area to distribute the different menus.

After the intervention, the restaurant used the control area menu (i.e., the one containing the meat and fish option only) in the whole restaurant for one week to control for trend effects.

\section{Data and results}

The intervention took place from May 2nd until May 20th, 2016. During that time, the restaurant was not serving the lunch menu for two days (Ascension Day and the Friday following it), resulting in 13 days of sales data with separate menus. Also, we collected total weekly sales of the three options for the four weeks before the intervention (April $4^{\text {th }}-30^{\text {th }}$ ) and for five days after the intervention (May $22^{\text {nd }}-27^{\text {th }}$ ). On average the restaurant sells 400 dishes

\footnotetext{
${ }^{2}$ The rearranging of the menu most likely influenced behavior through several behavioral channels other than pure convenience. The experimental design and the resulting data does not allow us to disentangle the different channels. However, section 4 provides a discussion on the potential mechanisms.
} 
per week, although there is some variation due to weather when the restaurant opens up their outdoor seating and can serve more customers in the two-hour lunch period. ${ }^{3}$

\section{3.a. The effect of menu design on food choice}

First, we show the aggregate results for the whole restaurant. We conduct Chi2-tests to test for changes in ordering behavior across the two periods. Figure 1 shows the sales shares of the meat, fish and vegetarian option for the four weeks before the intervention, the three experimental weeks and the one-week post-experimental period. On average, only $2.5 \%$ of all dishes sold are vegetarian without the vegetarian option on the menu. The remaining lunches sold are distributed approximately equal across the meat and the fish dishes. In the weeks of the intervention (1-3) the share of meat dishes sold overall drops from $47 \%$ on average to $34 \%$ on average, a reduction of $38 \%(\mathrm{p}<0.01)$. Especially when considering that only approximately half of the restaurant got treated, this is a large reduction and stays consistent over the three weeks of the experiment. The vegetarian dishes jump from $3 \%$ to $9 \%$ on average (a $300 \%$ increase, $\mathrm{p}<0.01$ ), but with a downward trend over time. The weekly sales of fish dishes steadily increase during the intervention. On average the increase is around eight percentage points, from $50 \%$ to $57 \%$ ( $\mathrm{p}<0.01$ ). A Chi2-test on changes in the overall distribution of meals across the treatment confirms that meal choices differed significantly between the two periods $(\mathrm{p}<0.01)$.

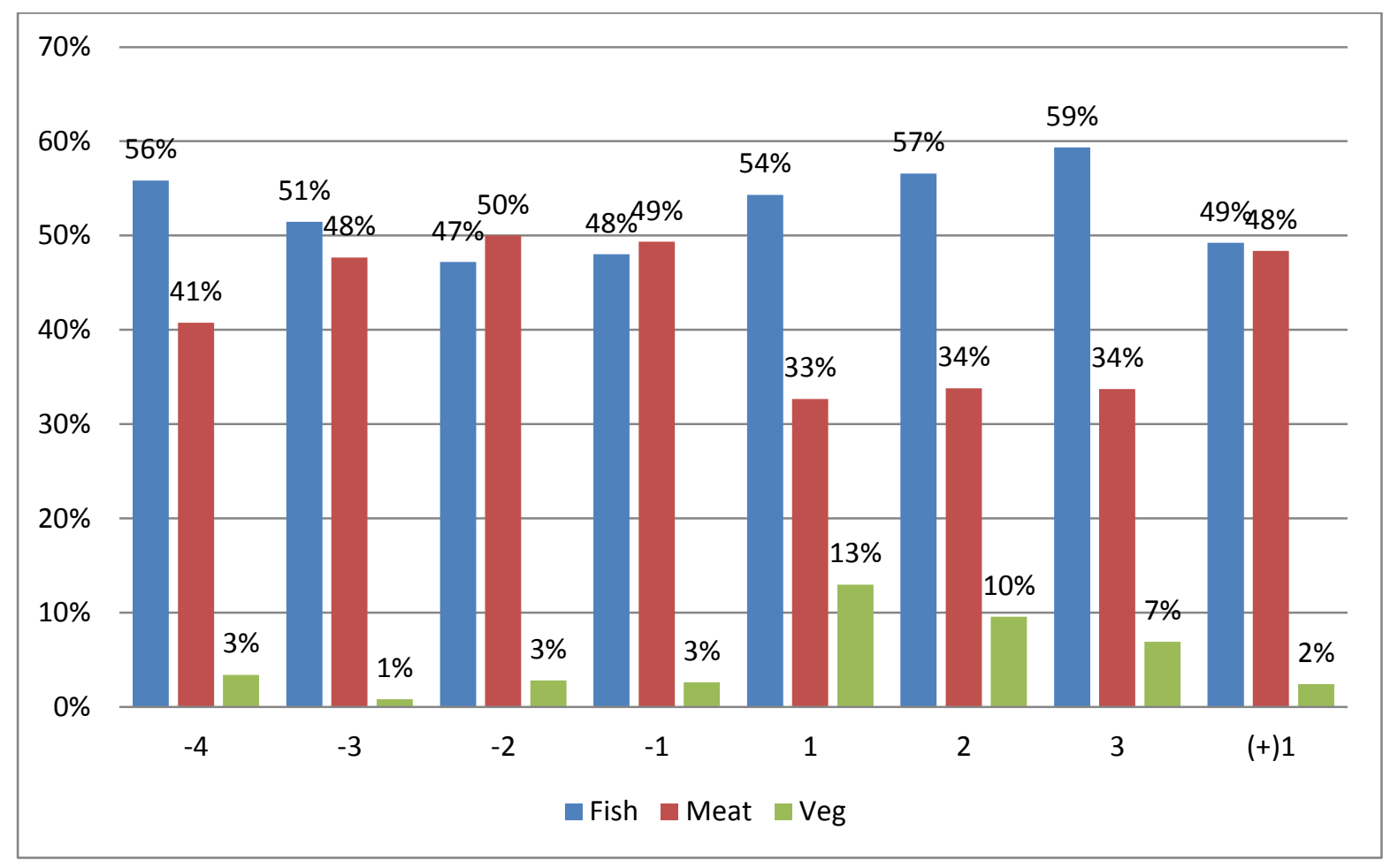

Figure 1 Shares of total sales. Intervention during weeks 1-3.

\footnotetext{
${ }^{3}$ As a result of opening the outdoor serving area, the number of total sales increased considerably starting with the second week of the intervention. However, the shares of the dishes sold at the different treatment areas seem to be unaffected by the opening of the outdoor serving.
} 
Second, we look at the sales for the two menus separately. Because absolute sales vary over days and weeks, we only show the percentage of sales in the figures for comparison, but we conduct Chi2-test using absolute values to test for differences in ordering behavior. All absolute values can be found in Table 1 in the Appendix. Figure 2 contains the sales shares for the three-week intervention period. The left panel shows the sales for the "meat" menu and the right panel for the "vegetarian" menu. Overall, meal choices differ significantly between the treated and the control area $(\mathrm{p}<0.01)$. The average share of vegetarian dishes sold jumps from on average 3\% before the intervention to $23 \%$ (an increase of 667\%) in the first week of the intervention in the area with the "vegetarian" menu ( $p<0.01)$. It remains low $(2 \%)$ in the "meat" menu area. The following two weeks, shares stay low at around $4 \%$ for the meat menu and reduce over time in the vegetarian menu area. Comparing average sales of vegetarian dishes over the whole intervention period shows that they are significantly different between the two areas of the restaurant. $15 \%$ of all dishes sold are vegetarian in the vegetarian area, while it is only around 3.5\% in the meat area ( $<<0.01)$. The share of meat dishes sold is $46 \%$ on average in the "meat" menu area and less than half of that in the "vegetarian" menu area $(21 \%, \mathrm{p}<0.01)$. This drop is larger than the increase in vegetarian sales shares, and consequently, also the share of fish dishes sold increases from around $51 \%$ to $64 \%$ ( $p<0.01$ ). Hence, approximately half of the consumers that switched away from the meat option substituted it with fish and the other half with vegetarian food.

Figure 2 shows a decrease of the treatment effect over time. While treatment effects are statistically significant when comparing the treated and the control area separately for each week (Chi 2 tests, $\mathrm{p}<0.01$ for each week), the share of vegetarian dishes sold decreases over time in the treated area. ${ }^{4}$ In the control area, no significant changes occurred during the intervention period.

\footnotetext{
${ }^{4}$ Chi2 tests show that distribution of choices is significantly changes over the three weeks of the intervention within the treated area. Testing for differences in the sales of vegetarian dishes per week shows that all weeks differ significantly from each other at least at a $10 \%$ level of significance.
} 

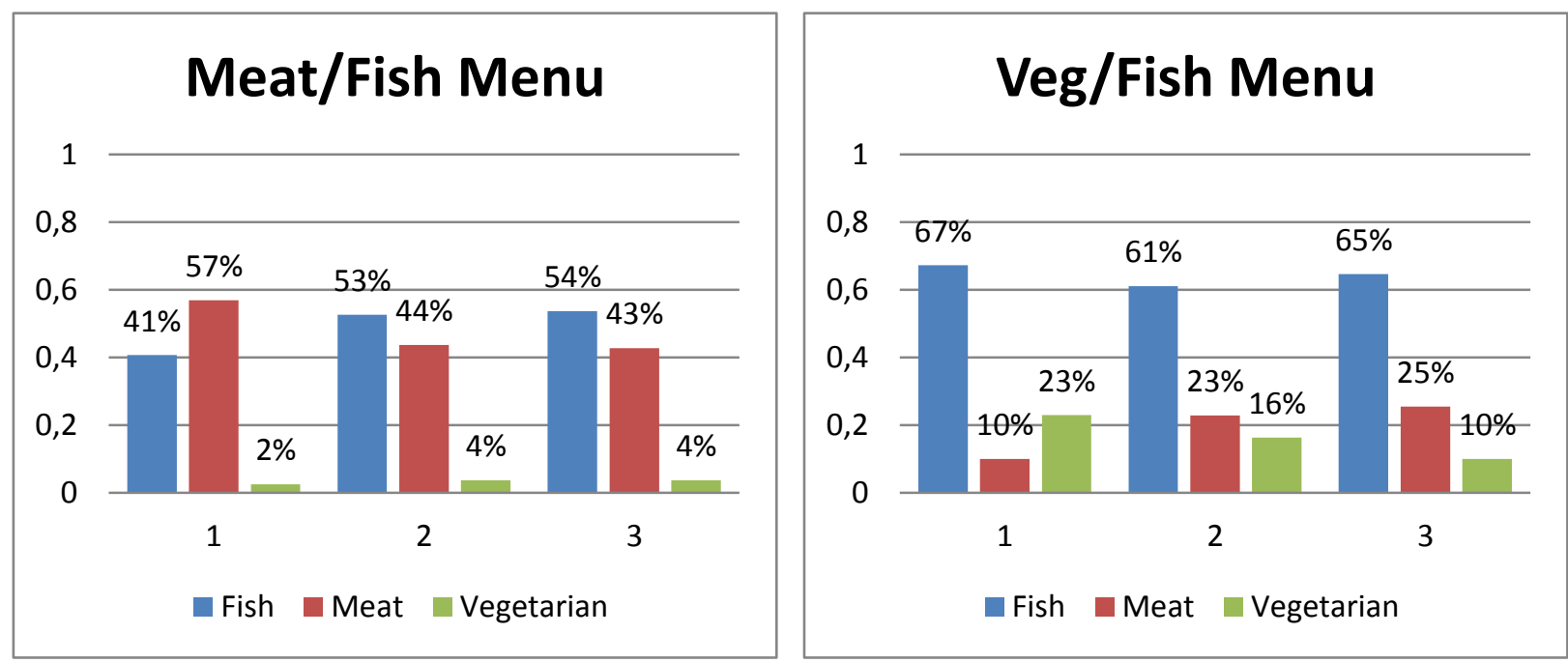

Figure $\mathbf{2}$ Share of sales for the two menus separately during the intervention period

What could cause such a trend in the treatment? One possible explanation is the presence of regular customers who have experience with the old menu. Although we might initially nudge those regular customers away from the meat, they are likely to switch back to their old choice patterns in case they do not like the option they were nudged into. The restaurant the experiment took place in reports having a quite high number of regular customers, around $20 \%$. Our data does not allow us to analyze the behavior of this interesting subject group for a longer period. The last three columns in Figure 1 show that switching to the old menu layout (but still keeping the note that a vegetarian dish was available) immediately restored the pretreatment sales shares. Hence, we conclude that there are no trend effects that could explain the variation created by the experiment and there are no long-lasting effects of the intervention.

A valid concern of the experimental set-up could be spillover effects between the two areas of the restaurant. That could be the case, for example, if customers observe the waiters serving vegetarian dishes to customers in the vegetarian menu area or meat-based dishes to the meat menu area and influencing their choice. Alternatively, similarly, regular customers who are once exposed to one of the menus and at a different time exposed to a different menu. Both types of spillovers would downward-bias our treatment effect. Our results can, therefore, be considered lower bounds of the true effect. Within the area and at the same table, there could also be reinforcing effects. If the first person is nudged to choose either meat or a vegetarian meal, then other at the table might follow suit. Since we have no information on the sequence that orders were placed, we cannot control for peer effects. It is, however, likely that peer effects are at play. Thus the direction of the bias is not clear. In a study with children Angelucci et al. (2015) found reinforcing choices but in a study with adults in a restaurant Ariely and Levav (2000) present evidence for a love of variety in group choices.

One point often raised when discussing nudging towards vegetarian food is that customers might not feel satiated or that they might use the healthy main course as an excuse to order an unhealthy dessert. We examined the number of desserts ordered for both groups, but as the total amount of desserts ordered are very low ( $\leq 6$ per day), it is impossible to test this hypothesis. Compared to the pre-experimental period the total sale of dessert did not increase. The menu price included still water, which is what most Scandinavians drink for lunch. There 
was no change in the additional beverages ordered during the experimental period. We thus find no evidence for any compensational behavior in our data. We, however, cannot rule out that individuals compensated in the afternoon or evening by eating more meat.

\section{3.b. The importance of being marginal}

When it comes to predicting and evaluating the success of nudging interventions, one of the most important questions is how many of the people in the target group are marginal(Coffman et al., 2014; Levitt et al., 2016). Only if enough people are sufficiently marginal, i.e. close to indifferent between two options, will a small nudge lead to a shift in behavior for a significant share of the group. Our intervention gives us some interesting information about the distribution of meat eaters in our sample population. Imagine a distribution with meat lovers on one side and vegetarians on the other side. From the pre-intervention data, we know that $2.5 \%$ of the sample population has a high preference for eating vegetarian. Even though there is no vegetarian dish mentioned on the menu, they ask for and order a vegetarian dish. Orders of the vegetarian dish do not increase much when a note that vegetarian food is available is added to the menu (3.5\%). On the other side, we have the meat lovers. When meat is made less convenient to order, we still see on average $21 \%$ of customers asking for the meat dish. Most likely, the distribution is skewed, with a larger density on the side of meat eaters. When we introduce the nudge, we see that $25 \%$ of the individuals who would have chosen meat if they had been presented with the meat menu, now choose either fish $(13 \%)$ or the vegetarian dish (12\%). The result shows that a bit more than 1 out of 10 people in our target group are sufficiently close to the margin between fish and meat and similarly 1 out of 10 is sufficiently close to the margin between vegetarian food and meat. Without the intervention, these 2 out of 10 people would choose the meat dish.

For the first three days of the intervention, we have data on the choices of customers that have been identified by the waiters as "regulars." These customers have all had experience with the previous menu of a choice of meat or fish and have likely tried both types of dishes at some point. It is thus unlikely that they would have been unaware of the possibility of a meat dish being available. Although the data is limited, it paints a clear picture. Of the "regulars" exposed to the vegetarian menu, 17 ordered fish and 6 ordered the vegetarian dish, and none ordered meat. From the ones exposed to the meat menu 17 ordered fish, 12 ordered the meat, and none ordered the vegetarian option. The shares match the total sales shares of that week. This finding is in contrast to Löfgren et al. (2012) who show that experienced users often override defaults and are thus harder to "nudge" by changing defaults than inexperienced users. Our results show that at least when initially exposed to a nudge, even experienced users change their behavior. However, the amount of data is too limited to draw firm conclusions on this point, and we do not know anything about the behavior of regulars that visit the restaurant more than once during our experiment. As mentioned above, experienced users could be one explanation for the declining of our treatment effect. More detailed information and longterm data on regulars are needed to investigate this further. After the intervention, the menu 
effect vanishes, so the marginal people revert to their usual state of choosing meat over fish and the vegetarian dish.

\section{Discussion and Conclusion}

We show that a simple and cheap rearrangement of the menu, introducing a small nonmonetary cost of ordering meat, can contribute towards a reduction in meat consumption without any measurable negative effects. ${ }^{5}$ By decreasing the convenience of ordering the meat option in a Swedish lunch restaurant, we managed to increase the share of vegetarian dishes sold significantly. This result is, however, not a one to one trade off, as around half of those customers nudged away from meat choose fish instead, but not vegetarian food. From a climate change perspective, this is still a positive change as eating fish entails less climaterelevant emissions per $\mathrm{kg}$ than most kinds of meat (Röös, 2014). ${ }^{6}$

How much of a climate impact does the intervention have? A short example can put it into perspective. On one occasion a piece of beef was replaced by a grilled cabbage. A conservative estimate of the $\mathrm{CO} 2$ emission of a $150 \mathrm{~g}$ piece of local beef is $1 \mathrm{~kg}$ (CleanMetrics 2011). For the cabbage it is $0.05 \mathrm{~kg}$. That day $42 \%$ of the people exposed to the meat menu ordered the beef, but only $16 \%$ of the ones presented with the vegetarian menu do so. With roughly 50 people in each group that are $21 \mathrm{kgs}$ of $\mathrm{CO} 2$ from meat in the meat menu group and only $8 \mathrm{kgs}$ from meat in the vegetarian menu group. To put this into perspective, average emissions from driving a car in Sweden, are around $0.16 \mathrm{~kg}$ of $\mathrm{CO} 2$ per $\mathrm{km}$. That means the savings from that day are enough to compensate for a car driving $81 \mathrm{~km}$. Clearly, the reduction in $\mathrm{CO} 2$ varies depending on the type of meat. Any overall evaluation of climate benefits also crucially depends on the assumption that customers do not compensate for having chosen a vegetarian lunch with indulging in meat later the day or the day after. To the best of our knowledge, there has been no experiment conducted yet that examines substitution effects of food over time. Complete information about food choices is quite challenging to obtain. Nevertheless, further research in that area is needed to identify total climate effects of nudges aiming at reducing meat consumption.

There are some psychological reasons why changing the convenience of options works so well in changing behavior. The most conservative economic interpretation is that we introduce a small non-monetary cost to the option that is not prominently displayed. The customer must stop a waiter to ask what the third option consists of. Since the waiter comes in any case to take the order, this is a minuscule cost, but might be enough to deter the marginal group from choosing this option. In this sense, our experiment is similar to Wisdom et al. (2010) who study sandwich choices in a fast-food restaurant. In their experiment, a set of unhealthy

\footnotetext{
${ }^{5}$ Anecdotally there were no complaints during the experimental period. If someone noticed a change in the menu, the staff replied that they were trying out some new dishes and this explanation was accepted by all customers. Since the sales data is dependent on weekday and weather, we cannot reliably test whether the intervention had an effect on sales, as sales only increased over time. We do know that no one left the restaurant after looking at the menu.

${ }^{6}$ Consuming fish entails less climate-relevant emissions than beef, lamb, pork and mixed meats (such as minced meat) and approximately equally much as chicken.
} 
sandwiches was made less convenient to order by either putting them on a menu that was put into a sealed folder or by listing them on a separate page than a set of "featured" sandwiches serving as an implicit default. The authors find that both interventions affected sandwich choice, with the first one (sealing parts of the menu) having a larger effect. The benefit of our study compared to Wisdom et al. (2010) is that customers in our study were not aware that they were taking part in a study. We can thus be certain that the choices we observe were not affected by a social image motivation. Furthermore, we believe our intervention is more subtle and more feasible for restaurants to carry out compared to sealing menus with stickers. An alternative explanation could be that the two options that are displayed create a social norm of what is "standard" to choose at this restaurant. Alternatively, the menu constitutes an implicit recommendation from the kitchen which dishes are the tastiest dishes (see for example Sunstein and Reisch (2014) for possible explanations of the default effect). In a laboratory experiment, Altman et al. (2013) investigate implicit recommendations and find that defaults work better when the interest of the decision maker and the default setter are closely aligned as well as when the decision maker has little information. In such a simple setting such as a restaurant, this does not seem to be very relevant. In contrary, the nudge works just as well on regulars, who have experience with the food at the restaurant and who should react less to implicit recommendations. A third channel is a decrease in the salience of the third option (Cohen and Babey, 2012; Wansink and Sobal, 2007). The two options that are written out might feature a lot more prominent in decision-making, and if individuals are inattentive when ordering, they might miss the possibility of a third option altogether. Further research is needed to identify the exact channel of how our intervention changes behavior. Neither the current experiment nor any other field experiment on defaults that we are aware of is testing for different explanations of the default effect.

We conclude that even in restaurants with a highly meat-affine population, there is room for decreasing the share of meat dishes sold for vegetarian and fish dishes without banning meat or changing prices. Adding a non-monetary convenience cost to the meat dish reduced the orders of meat dishes by half in our setting. Clearly, it would be interesting to validate the effect size in other settings and investigate more long-term effects and possible spillovers to other purchases. Kurz (2016) investigates long-term effects of a change in menu order and finds a persistent effect over the course of three months. The sizable results in our experiment are a promising first step in reducing meat consumption in a fast, easy and profit-stable way. ${ }^{7}$

Our results show that nudging is a promising tool to influence food choice. However, to determine whether a similar nudge will work in a different setting one needs to consider the size of the marginal group in the target population. Restaurants which are either known for catering to vegetarians or meat-focused venues such as a steakhouse will most likely see smaller effects of the same intervention due to self-selection of the patrons into the restaurant, thus having a smaller proportion of marginal customers. The most promising settings are thus res-

\footnotetext{
${ }^{7}$ According to the restaurant's management, purchasing costs are around 30\% lower for vegetarian than for meat dishes. Preparation of vegetarian dishes is slightly more time-consuming than producing the other dishes, so personnel costs are higher. However, taking all costs into account, it is not more expensive to produce vegetarian dishes than meat or fish dishes. Overall, the management deemed the intervention to have positive effects on profits, but could not quantify the magnitude of this effect.
} 
taurants that attract customers based on their quality of food and not on their focus of meat vs. vegetarian food. In our sample, 1 out of 10 people would switch from meat to vegetarian food if it is made convenient and salient. So for any restaurant hoping to reduce their climate impact, a clear policy recommendation is to have a vegetarian choice available and make it a prominent choice on the menu. Restaurants should not present vegetarian food as a "special diet" that customers with special needs need to inquire about in the kitchen, thus creating hassle costs which will tip the people on the margin towards choosing the "normal" meat dish instead. Even half of the effect size that we find in this experiment would lead to significant reductions in $\mathrm{CO} 2$ and possible health effects for the marginal group. While we cannot rule out any negative spillover effects, our evidence points towards the contrary with stable sales and higher profit. Especially when comparing our intervention with a reduction of choice by banning the meat option, which would also restrict the non-marginal people to choosing a vegetarian dish, the adverse reactions will very likely be lower. Nevertheless, more research is needed to verify these hypotheses. Governments, cities or private sector agents that want to limit the climate impact of food consumption should work proactively with restaurants to develop, implement and test customized nudging strategies to realize the potential gains from this approach. 


\section{References}

Altmann, S., Falk, A., Grunewald, A., 2013. Incentives and Information as Driving Forces of Default Effects. IZA Discussion Paper 7610, Institute for the Study of Labor (IZA).

Angelucci, M., Prina, S., Royer, H., Samek, A., 2015. When Incentives Backfire: Spillover Effects in Food Choice (Working Paper No. 21481). National Bureau of Economic Research.

Ariely, D., Levav, J., 2000. Sequential Choice in Group Settings: Taking the Road Less Traveled and Less Enjoyed. Journal of Consumer Research 27, 279-290. doi:10.1086/317585

Bryngelsson, D., Wirsenius, S., Hedenus, F., Sonesson, U., 2016. How can the EU climate targets be met? A combined analysis of technological and demand-side changes in food and agriculture. Food Policy 59, 152-164. doi:10.1016/j.foodpol.2015.12.012

Coffman, L.C., Featherstone, C.R., Kessler, J.B., 2014. Can Social Information Affect What Job You Choose and Keep? A Field Experiment in the United States (Mimeo).

Cohen, D.A., Babey, S.H., 2012. Contextual influences on eating behaviours: heuristic processing and dietary choices. Obesity Reviews 13, 766-779. doi:10.1111/j.1467-789X.2012.01001.x

Girod, B., van Vuuren, D.P., Hertwich, E.G., 2014. Climate policy through changing consumption choices: Options and obstacles for reducing greenhouse gas emissions. Global Environmental Change 25, 5-15. doi:10.1016/j.gloenvcha.2014.01.004

Just, D.R., 2009. Smarter lunchrooms: using behavioral economics to improve meal selection. CHOICES 24, 1.

Kurz, V., 2016. Nudging to reduce meat consumption: Immediate and persistent effects of an intervention at university cafeterias (Mimeo).

Lehner, M., Mont, O., Heiskanen, E., 2015. Nudging - A promising tool for sustainable consumption behaviour? Journal of Cleaner Production. doi:10.1016/j.jclepro.2015.11.086

Levitt, S.D., List, J.A., Sadoff, S., 2016. The Effect of Performance-Based Incentives on Educational Achievement: Evidence from a Randomized Experiment (Working Paper No. 22107). National Bureau of Economic Research.

Löfgren, Å., Martinsson, P., Hennlock, M., Sterner, T., 2012. Are experienced people affected by a pre-set default option - Results from a field experiment. Journal of Environmental Economics and Management 63, 66-72. doi:10.1016/j.jeem.2011.06.002

Lombardini, C., Lankoski, L., 2013. Forced Choice Restriction in Promoting Sustainable Food Consumption: Intended and Unintended Effects of the Mandatory Vegetarian Day in Helsinki Schools. J Consum Policy 36, 159-178. doi:10.1007/s10603-013-9221-5

Röös, E., 2014. Mat-klimat-listan (Report No. 77). Uppsala.

Säll, S., Gren, I.-M., 2015. Effects of an environmental tax on meat and dairy consumption in Sweden. Food Policy 55, 41-53. doi:10.1016/j.foodpol.2015.05.008

Slovic, P., 1995. The construction of preference. American Psychologist 50, 364-371. doi:10.1037/0003-066X.50.5.364

Springmann, M., Godfray, H.C.J., Rayner, M., Scarborough, P., 2016. Analysis and valuation of the health and climate change cobenefits of dietary change. PNAS 113, 4146-4151. doi:10.1073/pnas.1523119113

Sunstein, C.R., Reisch, L.A., 2014. Automatically Green: Behavioral Economics and Environmental Protection. Harv. Envtl. L. Rev. 38, 127.

Thaler, R.H., Sunstein, C.R., 2008. Nudge: improving decisions about health, wealth, and happiness. Yale University Press, New Haven.

Tilman, D., Clark, M., 2014. Global diets link environmental sustainability and human health. Nature 515, 518-522. doi:10.1038/nature13959

Tversky, A., Simonson, I., 1993. Context-Dependent Preferences. Management Science 39, 1179 1189.

Wansink, B., 2004. Environmental Factors that Unknowingly Increase a Consumer's Food Intake and Consumption Volume (SSRN Scholarly Paper No. ID 518902). Social Science Research Network, Rochester, NY.

Wansink, B., Hanks, A.S., 2013. Slim by Design: Serving Healthy Foods First in Buffet Lines Improves Overall Meal Selection. PLOS ONE 8, e77055. doi:10.1371/journal.pone.0077055 
Wansink, B., Sobal, J., 2007. Mindless Eating The 200 Daily Food Decisions We Overlook. Environment and Behavior 39, 106-123. doi:10.1177/0013916506295573

Westhoek, H., Lesschen, J.P., Rood, T., Wagner, S., De Marco, A., Murphy-Bokern, D., Leip, A., van Grinsven, H., Sutton, M.A., Oenema, O., 2014. Food choices, health and environment: Effects of cutting Europe's meat and dairy intake. Global Environmental Change 26, 196-205. doi:10.1016/j.gloenvcha.2014.02.004

Wirsenius, S., Hedenus, F., Mohlin, K., 2011. Greenhouse gas taxes on animal food products: rationale, tax scheme and climate mitigation effects. Climatic Change 108, 159-184. doi:10.1007/s10584-010-9971-x

Wisdom, J., Downs, J.S., Loewenstein, G., 2010. Promoting Healthy Choices: Information versus Convenience. American Economic Journal: Applied Economics 2, 164-78.

doi:10.1257/app.2.2.164 
Appendix

Table 1: Total sales and sales shares in percent of the three lunch options available across periods and treatments

\begin{tabular}{|c|c|c|c|c|c|c|c|c|c|}
\hline & & \multicolumn{2}{|c|}{ Meat } & \multicolumn{2}{|c|}{ Fish } & \multicolumn{2}{|c|}{ Vegetarian } & \multicolumn{2}{|c|}{ Total } \\
\hline \multicolumn{2}{|c|}{ Convenient option to order ${ }^{a}$} & Meat & $\mathrm{Veg}$ & Meat & Veg & Meat & $\mathrm{Veg}$ & Meat & Veg \\
\hline \multirow{10}{*}{$\begin{array}{l}\text { Baseline } \\
\text { period }\end{array}$} & Week 1 & 119 & & 163 & & 10 & & 292 & \\
\hline & & $40.75 \%$ & & $55.82 \%$ & & $3.42 \%$ & & $100 \%$ & \\
\hline & Week 2 & 113 & & 122 & & 2 & & 237 & \\
\hline & & $47.68 \%$ & & $51.48 \%$ & & $0.84 \%$ & & $100 \%$ & \\
\hline & Week 3 & 160 & & 151 & & 9 & & 320 & \\
\hline & & $50.00 \%$ & & $47.19 \%$ & & $2.81 \%$ & & $100 \%$ & \\
\hline & Week 4 & 187 & & 182 & & 10 & & 379 & \\
\hline & & $49.34 \%$ & & $48.02 \%$ & & $2.64 \%$ & & $100 \%$ & \\
\hline & Total & 579 & & 618 & & 31 & & 1228 & \\
\hline & & $47.15 \%$ & & $50.33 \%$ & & $2.52 \%$ & & $100 \%$ & \\
\hline \multirow[t]{8}{*}{ Intervention } & Week 1 ( 3 days) & 70 & 13 & 50 & 88 & 3 & 30 & 123 & 131 \\
\hline & & $56.91 \%$ & $9.92 \%$ & $40.65 \%$ & $67.18 \%$ & $2.44 \%$ & $22.90 \%$ & $100 \%$ & $100 \%$ \\
\hline & Week 2 & 142 & 66 & 171 & 177 & 12 & 47 & 325 & 290 \\
\hline & & $43.69 \%$ & $22.76 \%$ & $52.62 \%$ & $61.03 \%$ & $3.69 \%$ & $16.21 \%$ & $100 \%$ & $100 \%$ \\
\hline & Week 3 & 106 & 69 & 133 & 175 & 9 & 27 & 248 & 271 \\
\hline & & $42.74 \%$ & $25.46 \%$ & $53.63 \%$ & $64.58 \%$ & $3.63 \%$ & $9.96 \%$ & $100 \%$ & $100 \%$ \\
\hline & Total & 318 & 148 & 354 & 440 & 24 & 104 & 696 & 692 \\
\hline & & $45.69 \%$ & $21.39 \%$ & $50.86 \%$ & $63.58 \%$ & $3.45 \%$ & $15.03 \%$ & $100 \%$ & $100 \%$ \\
\hline \multirow[t]{2}{*}{ Post-Intervention } & Total (5 days) & 285 & & 280 & & 14 & & 579 & \\
\hline & & $49.22 \%$ & & $48.36 \%$ & & $2.42 \%$ & & $100 \%$ & \\
\hline
\end{tabular}

${ }^{\mathrm{a}}$ The fish option was equally convenient to order across periods and treatments and is therefore omitted from the column labeling. 